UVX 2010 (2011) 209-212

DOI: $10.1051 / \mathrm{uvx} / 2011030$

(C) Owned by the authors, published by EDP Sciences, 2011

\title{
Temporal coherence measurements of a seeded GRIP transient Ni-like Mo soft X-ray laser
}

\author{
L.M. Meng ${ }^{1}$, D. Alessi², O. Guilbaud ${ }^{3}$, Y. Wang ${ }^{2}$, S. Domingue ${ }^{2}$, B. Luther², \\ J.J. Rocca ${ }^{2}$ and A. Klisnick ${ }^{1}$ \\ ${ }^{1}$ ISMO, Bât. 350, CNRS, Université Paris-Sud 11, Orsay, France \\ ${ }^{2}$ NSF Center for EUV Science and Technology Colorado State University, Fort Collins, USA \\ ${ }^{3}$ LPGP, Bât. 210, CNRS, Université Paris-Sud 11, Orsay, France
}

\begin{abstract}
The temporal coherence of seeded and unseeded GRIP transient Ni-like Mo X-ray laser emitting at $18.9 \mathrm{~nm}$ was investigated by a wavefront division interferometer. The coherence time of the X-ray laser pulse is found to be of the order of $1.7 \mathrm{ps}$ in the ASE mode and slightly smaller when the amplifier is seeded with a high-order harmonic pulse. The spectral line width is subject to a gain narrowing when increasing the length of the plasma amplifier.
\end{abstract}

\section{INTRODUCTION}

X-ray lasers are widely used in lithography, high resolution imaging, phase coherent probing of atomic and molecular systems, and structural biology [1]. These applications are effected by the spatial and temporal coherence of these sources. Recent works report some exciting results for high quality x-ray laser [2-4]. The most interesting progress is the injection-seeded $x$-ray laser [5,6]. More attention is paid for the temporal coherence and the spectral width of these kinds of laser.

In this report, we will discuss the spectral properties of a nickel-like molybdenum X-ray laser [7]. We will first briefly recall the conditions of the experiment, and then discuss the analysis of the experimental data. The variation of fringe visibility as a function of the path difference between the interfering X-ray laser beams was used to infer the temporal coherence length [8]. We will show how the spectral profile of the laser line was deduced from the experimental measurement of the temporal coherence [9].

\section{EXPERIMENTAL SETUP}

The experiment was carried out at the NSF Center for EUV Science and Technology, Colorado State University, USA, during July 2009. We have studied a Ni-like Mo X-ray laser beam at $18.9 \mathrm{~nm}$, seeded with a high-order harmonic pulse, as described in [7].

The X-ray laser beam was directed toward a wavefront division interferometer specifically designed for measuring the temporal coherence. This diagnostic was placed at a distance of $3.3 \mathrm{~m}$ from the source, in order to ensure a significant transverse coherence length of the beam at the entrance of the interferometer. A complete description of this interferometer can be found in [8]. The incident beam, with a $6^{\circ}$ grazing incidence angle, is reflected on a pair of dihedrons into two separated half-beams that slightly converge towards each other and overlap. The fringes that are formed in the overlapping region are detected onto an XUV CCD $(1024 \times 1024$ pixels, 16 bits, Andor Technology $)$ which is placed at

This is an Open Access article distributed under the terms of the Creative Commons Attribution-Noncommercial License 3.0, which permits unrestricted use, distribution, and reproduction in any noncommercial medium, provided the original work is properly cited. 
$150 \mathrm{~cm}$ from the dihedrons, and tilted at an angle of $35^{\circ}$ from the incident beam in order to increase the apparent fringe spacing. The path difference between the two interfering half-beams was varied from shot to shot by accurately translating one of the two dihedrons vertically.

\section{RESULTS}

Figure 1 presents typical interferograms, obtained with the path difference set to zero, and a plasma length of $4 \mathrm{~mm}$, in either the seeded mode (Fig. 1(a) or the ASE mode (Fig. 1(b).

The interferograms obtained for increasing values of the path difference were processed numerically, in a zone containing the interference fringes, by applying a background subtraction, followed by a numerical Fourier transform processing performed with a small sliding window. This yields the map of the local fringe visibility $\mathrm{V}(\mathrm{x}, \mathrm{y})$ over the interference field.

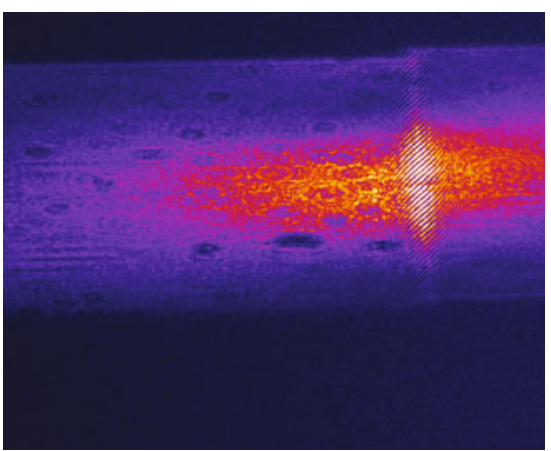

(a)

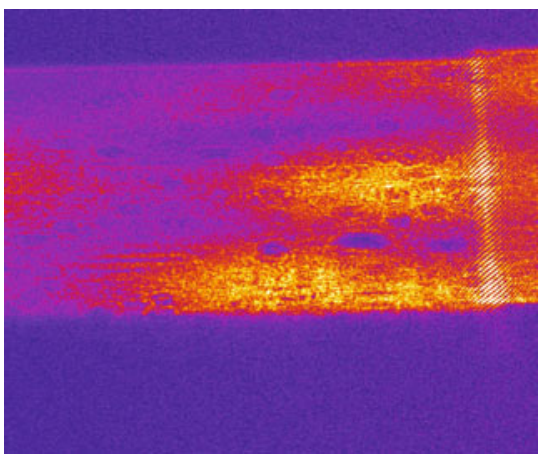

(b)

Figure 1. Interferograms of the X-ray laser beam: (a)seeded mode, (b) ASE mode, for a plasma length is $4 \mathrm{~mm}$.

Figure 2 shows the graphs of the measured fringe visibility $\mathrm{V}(l)$ as a function of the path difference $l$, for 3 different lengths of the plasma amplifier in which the harmonic pulse is injected: $2 \mathrm{~mm}$ (Fig. 2(a)), $3 \mathrm{~mm}$ (Fig. 2(b)), $4 \mathrm{~mm}$ (Fig. 2(c)). Figure 2(d) shows the same measurement performed with a $4 \mathrm{~mm}$ plasma length in Amplification of Spontaneous Emission (ASE) mode.

Several shots were performed for each value of the path difference, at fixed irradiation conditions. The black squares plotted in Figure 2 are the shot-averaged value of the measured visibilities for each path difference $l$. The vertical error bars give the visibility standard deviation. One can see that the fringe visibility for $l=0 \mu \mathrm{m}$ is smaller than 1 . That is because the seeded and ASE laser sources are partially spatially coherent. On the other hand the visibility is strongly reduced while increasing the path difference from $0 \mathrm{~mm}$ to $0.5 \mathrm{~mm}$ ( or $10^{4} \lambda$ ). The experimental data were then fitted with a linear superposition of Gaussian and exponentially decreasing functions. The corresponding curves, which gave the best fitting coefficients, are shown by the solid lines on Figures 2.

The values of the longitudinal coherence length $\mathrm{L}_{\mathrm{C}}$, which is defined as the path difference that decreases the maximal visibility by a factor 1/e, are summarized in Table 1 for the 4 cases shown in Figures 2.

Using the Wiener-Khintchine theorem [10], which states that the spectral line profile $\rho(v)$ is proportional to the Fourier transform of the longitudinal degree of coherence $\gamma(\tau)$, the spectral width and the profile of the laser line can be deduced from the visibility curve.

Table 1 shows the values of the FWHM line width $\Delta v$ and $\Delta \lambda$, from which it can be seen that the measured line width is of the order of $3 \mathrm{~m} \AA$. For the $4 \mathrm{~mm}$ plasma, it is slightly smaller in the ASE mode than in the seeded mode. The spectral line width is observed to decrease slightly, when increasing the 


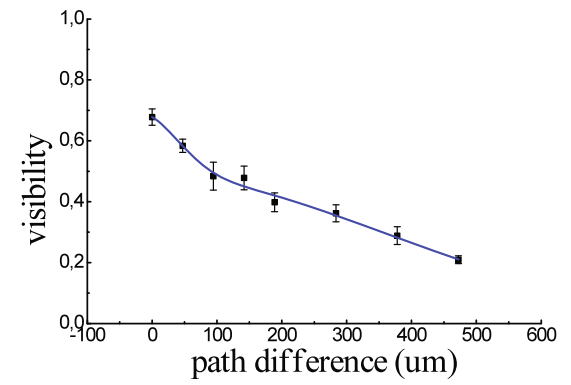

(a)

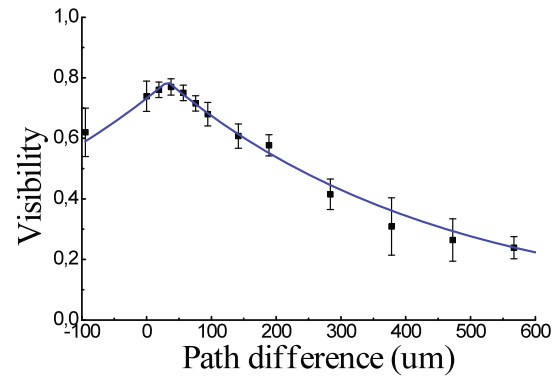

(c)

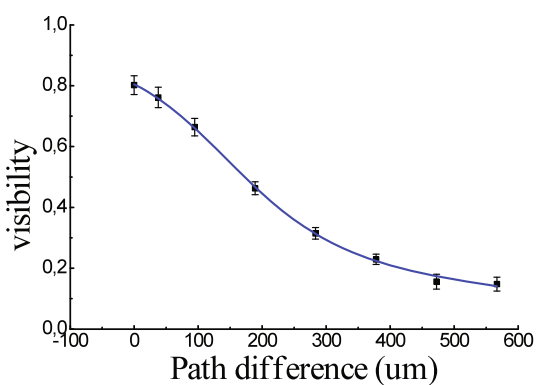

(b)

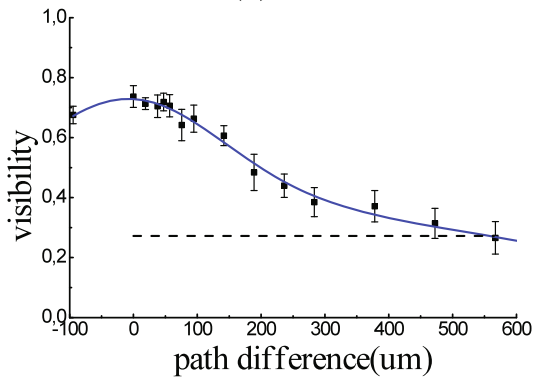

(d)

Figure 2. Fringe visibility (l) as a function of the path difference $l$ : (a) plasma length $2 \mathrm{~mm}$, seeded mode, (b) plasma length $3 \mathrm{~mm}$, seeded mode, (c) plasma length $4 \mathrm{~mm}$, seeded mode, (d) plasma length $4 \mathrm{~mm}$, ASE mode.

Table 1. Summary of the measured coherence length and spectral width.

\begin{tabular}{|l|c|c|c|c|}
\hline Mode & Seeded & Seeded & Seeded & ASE \\
\hline $\begin{array}{l}\text { Plasma length L } \\
(\mathrm{mm})\end{array}$ & 2 & 3 & 4 & 4 \\
\hline $\begin{array}{l}\text { Coherent length Lc } \\
(\mu \mathrm{m})\end{array}$ & $440 \pm 50$ & $298 \pm 28$ & $424 \pm 65$ & $495 \pm 70$ \\
\hline $\begin{array}{l}\text { Coherence time } \tau_{\mathrm{c}} \\
(\mathrm{ps})\end{array}$ & $1.46 \pm 0.16$ & $0.99 \pm 0.09$ & $1.41 \pm 0.22$ & $1.65 \pm 0.24$ \\
\hline Line width $\lambda(\mathrm{m} \AA)$ & $3.7 \pm 0.3$ & $3.1 \pm 0.5$ & $2.7 \pm 0.4$ & $2.6 \pm 0.4$ \\
\hline $\begin{array}{l}\text { Spectral width } \\
\Delta v\left(10^{11} \mathrm{~Hz}\right)\end{array}$ & $3.11 \pm 0.25$ & $2.60 \pm 0.42$ & $2.27 \pm 0.34$ & $2.18 \pm 0.34$ \\
\hline
\end{tabular}

length of the plasma amplifier from $2 \mathrm{~mm}$ to $4 \mathrm{~mm}$. Such behaviour is consistent with gain narrowing and was already observed in another experiment performed with the OFI seeded X-ray laser [4,11].

By comparing in Table 1 the values of the spectral width to the corresponding values of the coherence length it can be noted that these two quantities do not exhibit the same behaviour. In particular, since we have mentioned that the line width is inversely proportional to the coherence length, we should observe that the coherence length increases when the length of the plasma gets larger. This apparent contradiction is due to the fact that different shapes of the visibility curves (hence spectral profiles) were used in each case (see Figures 2), yielding different numerical factors relating Lc to $\Delta v$ (FWHM). In order to overcome this problem, we have used another definition for these two quantities, based on quadratic means, which are less sensitive to the choice of the fitting function used to describe the experimental data. This analysis of the data is described in [12]. 


\section{CONCLUSION}

We have measured the line width of the $18.9 \mathrm{~nm}$ Mo X-ray laser, in both the seeded mode and the ASE mode, and for several lengths of the plasma amplifier. We have observed gain narrowing of the line width when increasing the amplifier length in seeded mode. For the same plasma length, the line width in seeded mode is a little larger than in the ASE mode, and the maximum visibility is a little larger. These conclusions are consistent with a previous experiment performed at LOA with an OFI-pumped $\mathrm{X}$-ray $[4,11]$.

\section{Acknowledgements}

The experiment performed at CSU was funded by the NSF Center for EUV Science and Technology under NSF Award Number EEC-0310717, and by the Chemical Sciences, Geosciences and Biosciences Division, Office of Basic Energy Sciences, Office of Science, U.S. Department of Energy.

\section{References}

[1] S. Suckewer and CH. Skinner, Science 247, (1990) 1553-1557.

[2] Y. Wang, M.A. Larotonda, B.M. Luther, D. Alessi, M. Berril, V.N.Shlyaptsev, J.J. Rocca, Phys. Rev. A 72, (2005) 053807(1-7).

[3] J.J. Rocca, Y. Wang, M.A. Larotonda, B.M. Luther, M. Berrill, and D. Alessi, Opt. Lett. 30, (2005) 2581-2583.

[4] F. Tissandier, S. Sebban, M. Ribiere, J. Gautier, Ph. Zeitoun, G. Lambert, A. Barszczak Sardinha, J.-Ph. Goddet, F. Burgy, T. Lefrou, C. Valentin, A. Rousse, O. Guilbaud, A. Klisnick, J. Nejdl, T. Mocek, G. Maynard, Phys. Rev. A. 81, (2010) 063833(1-4).

[5] Ph. Zeitoun, G. Faivre, S. Sebban, T. Mocek, A. Hallou, M. Fajardo, D. Aubert, Ph. Balcou, F. Burgy, D. Douillet, S. Kazamias, G. de Lacheze-Murel, T. Lefrou, S. le Pape, P. Mercere1, H. Merdji, A. S. Morlens, J. P. Rousseau \& C. Valentin, Nature 431, (2004) 426-429.

[6] Y. Wang, E. Granados, M. A. Larotonda, M. Berrill, B. M. Luther, D. Patel, C. S. Menoni, and J. J. Rocca, Phys.Rev. Lett. 97, (2006) 123901.

[7] Y. Wang, E. Granados, F. Pedaci1, D. Alessi, B. Luther, M. Berrill, J. J. Rocca, Nature Photonics 2, (2008) $94(1-5)$.

[8] A. Klisnick, O. Guilbaud, D. Ros, K. Cassou, S. Kazamias, G. Jamelot, J.-C. Lagron, D. Joyeux, D. Phalippou, Y. Lechantre, M. Edwards, P. Mistry and G.J. Tallents, J.Q.S.R.T., 99, (2006) 370-380.

[9] O. Guilbaud, A. Klisnick, D. Joyeux, D. Benredjem, K. Cassou, S. Kazamias, D. Ros, D. Phalippou, G. Jamelot and C. Möller, Eur. Phys. J. D 40, (2006) 125-132.

[10] Born, M et al.: Principles of optics. Cambridge University Press, London, 2002, pp 321.

[11] O. Guilbaud, F. Tissandier, J-P. Goddet, M. Ribière, S. Sebban, J. Gautier, D. Joyeux, D. Ros, K. Cassou, S. Kazamias, A. Klisnick, J. Habib, P. Zeitoun, D. Benredjem, T. Mocek, J. Nedj, S. de Rossi, G. Maynard, B. Cros, A. Boudaa, and A. Calisti, Opt. Lett, 35 (2010) 1326-1328.

[12] L.M. Meng, D. Alessi, O. Guilbaud, Y. Wang, M. Berrill, B.M. Luther, S.R. Domingue, D.H. Martz, D. Joyeux, S. De Rossi, J.J. Rocca, and A. Klisnick, submitted to Opt. Lett. (2010). 